\title{
Identifying Metabolites of Meclonazepam by High-Resolution Mass Spectrometry Using Human Liver Microsomes, Hepatocytes, a Mouse Model, and Authentic Urine Samples
}

\author{
Svante Vikingsson, ${ }^{1,2,4}$ (D) Ariane Wohlfarth, ${ }^{1,2}$ Mikael Andersson, ${ }^{2}$ Henrik Gréen, ${ }^{1,2}$ Markus Roman, ${ }^{2}$ \\ Martin Josefsson, ${ }^{2,3}$ Fredrik C Kugelberg, ${ }^{1,2}$ and Robert Kronstrand ${ }^{1,2}$
}

Received 20 October 2016; accepted 28 December 2016; published online 13 January 2017

\begin{abstract}
Meclonazepam is a benzodiazepine patented in 1977 to treat parasitic worms, which recently appeared as a designer benzodiazepine and drug of abuse. The aim of this study was to identify metabolites suitable as biomarkers of drug intake in urine using highresolution mass spectrometry, authentic urine samples, and different model systems including human liver microsomes, cryopreserved hepatocytes, and a mice model. The main metabolites of meclonazepam found in human urine were amino-meclonazepam and acetamido-meclonazepam; also, minor peaks for meclonazepam were observed in three of four urine samples. These observations are consistent with meclonazepam having a metabolism similar to that of other nitro containing benzodiazepines such as clonazepam, flunitrazepam, and nitrazepam. Both metabolites were produced by the hepatocytes and in the mice model, but the human liver microsomes were only capable of producing minor amounts of the amino metabolite. However, under nitrogen, the amount of aminomeclonazepam produced increased 140 times. This study comprehensively elucidated meclonazepam metabolism and also illustrates that careful selection of in vitro model systems for drug metabolism is needed, always taking into account the expected metabolism of the tested drug.
\end{abstract}

KEY WORDS: benzodiazepine; in vitro metabolism; LC-MS/MS; new psychoactive substance; toxicokinetics.

\section{INTRODUCTION}

Meclonazepam, also known as (S)-3-methylclonazepam, RO 11-3128, or RO 11-3624, is a benzodiazepine developed and patented by Hoffman-La Roche in 1977 (1) and recently introduced as a drug of abuse (2). Benzodiazepines are of forensic interest for several reasons. Many are widely prescribed drugs used for legit purposes, but benzodiazepines

Svante Vikingsson and Ariane Wohlfarth contributed equally to this manuscript.

$\overline{\text { Electronic supplementary material The online version of this article }}$ (doi:10.1208/s12248-016-0040-x) contains supplementary material, which is available to authorized users.

\footnotetext{
${ }^{1}$ Clinical Pharmacology, Division of Drug Research, Department of Medical and Health Sciences, Linköping University, Linköping, Sweden.

${ }^{2}$ Department of Forensic Genetics and Forensic Toxicology, National Board of Forensic Medicine, Linköping, Sweden.

${ }^{3}$ Department of Physics, Chemistry and Biology, Linköping University, Linköping, Sweden.

${ }^{4}$ To whom correspondence should be addressed. (e-mail: svante.vikingsson@liu.se)
}

are also encountered in drug facilitated sexual assaults (3), over-dose cases, and lethal intoxications, in the latter often together with opioids (4).

The pharmacology of meclonazepam has been investigated in clinical trials as an anxiolytic (5) and, interestingly, as a schistosomicidal drug to treat the parasitic worms Schistosoma haematobium and Schistosoma Mansori $(6,7)$. Meclonazepam can successfully cure parasitic infections with a single dose of at least $0.3 \mathrm{mg} / \mathrm{kg}$, but clinical tolerance was limited by severe adverse drug effects including drowsiness, dizziness, slurred speech, ataxia, muscle weakness, reduced mental alertness, and lateral nystagmus (7). The effects are dose dependent with a narrow therapeutic window; a dose of $0.1 \mathrm{mg} / \mathrm{kg}$ result in no detectable adverse drug effects, $0.3 \mathrm{mg} /$ $\mathrm{kg}$ in mild to moderate adverse drug effects, and doses above $0.4 \mathrm{mg} / \mathrm{kg}$ give severe adverse drug effects (7). Boyle et al. (8) reported that meclonazepam showed adverse drug effects typical of benzodiazepines, such as clumsiness, feebleness, drowsiness, and mental slowness, with the most pronounced effects within $3 \mathrm{~h}$ of oral dosing $>1 \mathrm{mg}$ as well as amnesia after a 4-mg dose. The adverse drug effects can be reversed by co-administration with flumazenil (9). As an anxiolytic, Ansseau et al. (5) report a potency three times that of 
diazepam in the conflict test in rats as well as potency similar to flunitrazepam in the in vivo benzodiazepine binding assay.

In a forensic setting, most drug tests are conducted using urine as this is a less intrusive matrix not requiring a medical professional for sampling with an often longer window of detection than in blood (10). The latter seems to hold true for nitro-containing benzodiazepines as illustrated for flunitrazepam by Forsman et al. (11). While flunitrazepam was undetectable in urine $12 \mathrm{~h}$ after a 0.5 -mg dose, at least one metabolite was detected in every case $120 \mathrm{~h}$ post-dosing (11), indicating a 10 times longer detection window of metabolites in urine.

There is limited data on the pharmacokinetics of meclonazepam. Based on data from a single patient published by Coassolo et al. (12), the bioavailability can be estimated to be close to $100 \%$, volume of distribution to be around $300 \mathrm{~L}$ and a plasma half-life approximately $80 \mathrm{~h}$. Ansseau et al. (5) report meclonazepam half-life to be $40 \mathrm{~h}$. Coassolo et al. (12) claim amino-meclonazepam, 3-methylhydroxy-meclonazepam, and amino-3-methylhydroxy-meclonazepam to be metabolites but provide no data (12). This is in agreement with Huppertz et al. (2) who described two metabolites generated in human liver microsome experiments, amino-meclonazepam, and a hydroxylated metabolite. Meyer et al. (13) analyzed urine samples of persons with suspected meclonazepam intake and found aminomeclonazepam and acetamido-meclonazepam but did not mention hydroxylated metabolites. This is in agreement with the metabolism of the unmethylated analog of meclonazepam, clonazepam, which is mainly metabolized by CYP3A4 to aminoclonazepam and then further by N acetyl transferase 2 (NAT2) into acetamido-clonazepam (14-16). This metabolic pathway has also been described for other nitro-containing benzodiazepines including flunitrazepam (11) and nitrazepam (15).

In summary, there are three papers $(2,12,13)$ providing possible metabolites of meclonazepam. However, their study designs are neither comparable nor complete and therefore the results are not consistent.

The aim of this study was to conduct a complete and comprehensive metabolite investigation to answer the questions about meclonazepam metabolism using authentic urine samples as well as verifying identified metabolites in an in vivo mice model and in vitro using human liver microsomes (HLM) and cryopreserved hepatocytes.

\section{MATERIAL AND METHODS}

Four authentic urine samples and a blank urine were analyzed by liquid chromatography-quadrupole time of flight mass spectrometry (LC-QTOF-MS). The analysis was repeated after hydrolysis with $\beta$-glucuronidase and aryl-sulfatase. The origin of identified metabolites was verified by collection of urine over $24 \mathrm{~h}$ from two mice exposed as well as in HLMs and hepatocytes incubated with meclonazepam. All samples were analyzed using the same methodology as the human urine samples.

\section{Analytes and Reagents}

Meclonazepam was obtained from Chiron A/S (Trondheim, Norway). Liquid chromatography-mass spectrometry (LC-MS) grade acetonitrile (ACN), formic acid, and methanol were purchased from Fisher Scientific (Gothenburg,
Sweden). Ammonium formate was obtained from Fluka (Sigma-Aldrich, Stockholm, Sweden) and $\beta$-glucuronidase/ arylsulfatase (Helix pomatia) from Roche (Mannheim, Germany). Saline ( $9 \mathrm{mg} / \mathrm{mL}$ sodium chloride) was from Braun (Melsungen, Germany) and 99.5\% ethanol from Kemetyl (Haninge, Sweden). HLM (UltraPool ${ }^{\mathrm{TM}}, 150$-donor-pool) and NADPH regenerating system solution $A$ and $B$ were purchased from Corning (Corning, NY, US), cryopreserved human hepatocytes (LiverPool ${ }^{\mathrm{TM}}$, 10-donor-pool), InVitro Gro HT, and InVitro Gro KHB media from BioreclamationIVT (Baltimore, MD, USA). High-purity water was produced in-house in a MilliQ Gradient 10 production unit from Millipore (Billerica, MA, USA).

\section{Human Urine Samples}

Four authentic human urine samples from case work at the National Board of Forensic Medicine were analyzed in this study. Two of them were driving under the influence of drugs (DUID) cases (H1, H2), and the other two were from cases involving violent crimes (H3, H4). Cases were identified by an accompanying whole blood sample positive for meclonazepam by LC-MS-QTOF (qualitatively verified, unpublished data).

Aliquots of $100 \mu \mathrm{L}$ of urine were diluted with $110 \mu \mathrm{L}$ of mobile phase A (see below) either directly or after hydrolysis with $10 \mu \mathrm{L}$ beta-glucuronidase/arylsulfatase for $1 \mathrm{~h}$ at $40{ }^{\circ} \mathrm{C}$. In the non-hydrolyzed set, $10 \mu \mathrm{L}$ water was added.

\section{Mice Experiments}

Animal studies were performed at the Center of Biomedical Resources at Linköping University. Male C57BL/6N mice of age 7-12 weeks weighing approximately $25 \mathrm{~g}$ were obtained from Charles River Laboratories (Sulzfeld, Germany) and were housed 4 per cage in an environmentally controlled room with a 12-h light/dark cycle. The mice had free access to water, containing $25 \mathrm{~g} / \mathrm{L}$ dextrosol to increase liquid consumption, and food. The protocol was approved by the Swedish Board of Agriculture's Animal Ethics Committee in Linköping, Sweden (Dnr 4914).

After i.p. injection of $1 \mathrm{mg} / \mathrm{kg}$ of meclonazepam, urine was separately collected from two mice in metabolic cages for $24 \mathrm{~h}$ (Tecniplast, Buguggiate, Italy) in which urine is separated from feces. The sample volumes at $24 \mathrm{~h}$ were $3-$ $4 \mathrm{~mL}$.

\section{In Vitro Incubations}

Meclonazepam of $10 \mu \mathrm{M}$ was incubated with $0.5 \mathrm{mg} / \mathrm{mL}$ HLM for up to 90 min using an NADPH regenerating system in potassium phosphate buffer $(0.1 \mathrm{M}, \mathrm{pH} 7.4)$ at $37^{\circ} \mathrm{C}$. The reaction was stopped by addition of ice-cold acetonitrile (100 to $50 \mu \mathrm{L}$ of incubation mixture) and the precipitate removed by centrifugation. The incubations with the HLM were also repeated under nitrogen flow. The reaction mixture (containing NADPH regenerating system, HLM, and potassium phosphate buffer) was purged with nitrogen gas for $20 \mathrm{~min}$ prior to starting the reaction by addition of meclonazepam. 
Under continuous flow of nitrogen, the reaction was carried out for $60 \mathrm{~min}$.

Meclonazepam was also incubated with cryopreserved hepatocytes $\left(1 \times 10^{\wedge} 6\right.$ cells $\left./ \mathrm{mL}\right)$ for up to $5 \mathrm{~h}$ in InVitro Gro $\mathrm{KHB}$ media at $37^{\circ} \mathrm{C}$. The reaction was stopped by addition of ice-cold acetonitrile (500- to $500-\mu \mathrm{L}$ sample). After centrifugation, the supernatant was diluted $1: 4$ with $0.05 \%$ formic acid and $5 \mathrm{mM}$ ammonium formate in $50 \%$ acetonitrile.

\section{LC-QTOF-MS Analysis}

The metabolites of meclonazepam were separated using an LC-QTOF-MS system consisting of an Agilent 1290 Infinity LC instrument and an Agilent 6550 quadrupole time-of-flight mass spectrometer with a JetStream interface (both from Agilent, Kista, Sweden). Gradient elution with $0.05 \%$ formic acid in $10 \mathrm{mM}$ ammonium formate (A) and $0.05 \%$ formic acid in acetonitrile (B) with a flow of $0.5 \mathrm{~mL} /$ min was used for the separation on an Acquity HSS T3 column $(150 \mathrm{~mm} \times 2.1 \mathrm{~mm}, 1.8 \mu \mathrm{m}$, Waters, Sollentuna, Sweden). After an initial period of $1 \%$ B for 0.6 min, a linear gradient from 5 to $50 \% \mathrm{~B}(0.7-8.0)$ was followed by another linear gradient from 50 to $95 \%$ B (8-10 min, held until $11 \mathrm{~min})$ and re-equilibration of the column $(1 \% \mathrm{~B}, 11.1-$ $12.0 \mathrm{~min})$.

MS-data was collected in positive electrospray mode (gas temperature, $150{ }^{\circ} \mathrm{C}$; gas flow, $18 \mathrm{~L} / \mathrm{min}$; nebulizer, $50 \mathrm{psi}$; sheath gas temperature, $375{ }^{\circ} \mathrm{C}$; sheath gas flow, $11 \mathrm{~L} / \mathrm{min}$ ) using auto-MS/MS, i.e., a data-dependent acquisition mode $(\mathrm{m} / \mathrm{z}, 100-950,5$ candidates selected for MS/MS in each cycle based on intensity). In a second run, a targeted approach based on a preferred list was used for possible meclonazepam metabolites to obtain higher-quality MS-spectra.

\section{Data Analysis}

Peaks were extracted using a Personal Compound Database and Library (PCDL) of possible metabolites based on the following biotransformations: nitro reduction, acetylation of a primary amine, mono-, di-, and trihydroxylations, dehydrogenation, dihydrodiol formation, oxidative dechlorination, glucuronidation, and aryl-sulfatation as well as combinations thereof (including carboxylic acid formation and ketone formation). Ammonium, sodium, and potassium adducts as well as the neutral loss of water or formyl groups were considered as well.

Peaks were filtered based on accurate mass, intensity, and in a second step average mass and presence in unrelated samples. Metabolites only found in the model systems, i.e., mice, HLM, and/or hepatocytes were excluded from the final results.

The resulting metabolite candidates were individually evaluated based on chromatographic peak quality, MS/MS spectra (were available), possibility of suggested biotransformation, and in source fragmentation. Seventeen possible meclonazepam metabolites (including the neutral loss of formyl for 12 of them and the neutral loss of water for one of them) were added to a preferred list for the second LCQTOF run.

\section{RESULTS}

From the raw data, 22,760 possible peaks were identified in the authentic urine samples. After filtering, 28 metabolite candidates remained, which after manual review were reduced to 13 as shown in supplemental Table I. Human metabolites of meclonazepam identified in at least one human urine and by at least one model system, either mice, HLM, and/or hepatocytes, are shown in Table I and Fig. 1.

Small amounts of parent compound were identified in three out of four human urines. Mass spectra were only obtained from the parent, Fig. 2, and the major metabolites amino-meclonazepam (M9, Fig. 3) and acetamidomeclonazepam (M11, Fig. 4). Apart from one dihydrodiol (M1) and one dihydrodiol acetamido metabolite (M6), all minor metabolites were second- or third-generation metabolites of amino-meclonazepam (M9). M9 could be further hydroxylated to yield M2, M3, M5, M7, and M13; two of these metabolites underwent dehydration to generate M8 and M12. We also found a signal for a dechlorinated and sulfated amino metabolite in two human urine samples, although this compound might originate from synthesis impurities.

Of the 13 metabolites identified in the human urine samples, three (M6, M9, and M11) were confirmed in mice urine, only one by HLM (M9), and two by hepatocytes (M9,

Table I. Metabolites Identified in Cases and Confirmed by Human Liver Microsomes, Hepatocytes, and/or the Mouse Model

\begin{tabular}{|c|c|c|c|c|c|c|c|c|c|c|c|c|}
\hline \multirow[t]{2}{*}{ \# } & \multirow{2}{*}{$\begin{array}{l}\text { RT } \\
(\mathrm{min})\end{array}$} & \multirow[t]{2}{*}{ Biotransformation formula } & \multirow{2}{*}{$\begin{array}{l}\text { HYD } \\
+/-\end{array}$} & \multicolumn{6}{|c|}{ Peak area $\left(\times 10^{\wedge} 3\right.$ counts $)$} & \multirow{2}{*}{$\begin{array}{l}\text { Mass (Da) } \\
\text { Diff (ppm) }\end{array}$} & \multirow{2}{*}{$\begin{array}{l}\mathrm{m} / \mathrm{z}^{\mathrm{a}} \\
\text { Adduct }\end{array}$} & \multirow{2}{*}{$\begin{array}{l}\text { HLM } \\
\text { Hep }\end{array}$} \\
\hline & & & & $\mathrm{H} 1$ & $\mathrm{H} 2$ & H3 & $\mathrm{H} 4$ & M1 & M2 & & & \\
\hline \multirow[t]{2}{*}{ M6 } & 5.20 & Acetamido + monohydroxy & - & & 542 & & & 139 & 92 & 357.1 & 358.1 & \\
\hline & & $\mathrm{C} 18 \mathrm{H} 16 \mathrm{Cl} \mathrm{N} 3 \mathrm{O} 3$ & + & & 203 & & & 133 & 58 & -2.0 & $\mathrm{H}+$ & \\
\hline \multirow[t]{2}{*}{ M9 } & 5.98 & Amino & - & 410 & 28,472 & 1980 & 3944 & 1616 & 1252 & 299.1 & 300.1 & HLM \\
\hline & & $\mathrm{C} 16 \mathrm{H} 14 \mathrm{Cl} \mathrm{N} 3 \mathrm{O}$ & + & 341 & 17,799 & 2544 & 3973 & 1630 & 1311 & -0.6 & $\mathrm{H}+$ & Hep \\
\hline \multirow[t]{2}{*}{ M11 } & 6.18 & Acetamido & - & 510 & 15,707 & 561 & 708 & 903 & 514 & 341.1 & 342.1 & \\
\hline & & $\mathrm{C} 18 \mathrm{H} 16 \mathrm{Cl} \mathrm{N} 3 \mathrm{O} 2$ & + & 411 & 8429 & 995 & 950 & 1089 & 684 & -1.4 & $\mathrm{H}+$ & Hep \\
\hline \multirow[t]{2}{*}{$\mathrm{P}$} & 8.81 & Parent & - & & 270 & & 124 & 75 & 103 & 329.1 & 330.1 & HLM \\
\hline & & $\mathrm{C} 16 \mathrm{H} 12 \mathrm{Cl} \mathrm{N} 3 \mathrm{O} 3$ & + & & 128 & 51 & 122 & 75 & 119 & -1.6 & $\mathrm{H}+$ & Hep \\
\hline \multicolumn{4}{|c|}{ Sum of signals in hydrolyzed sample } & 751 & 26,559 & 3590 & 5045 & 2927 & 2172 & & & \\
\hline
\end{tabular}

Diff difference between measured and theoretical mass, Hep cryopreserved hepatocytes, HLM human liver microsomes, HYD hydrolysis with glucuronidase, $p p m$ parts per million, $R T$ average retention time

${ }^{a} \mathrm{~m} / \mathrm{z}$ values and adduct given for most prominent ion species 
<smiles>CC(=O)Nc1ccc2c(c1)C(c1ccccc1Cl)=N[C@@H](C)C(=O)N2</smiles>

meclonazepam

amino-meclonazepam

acetamido-meclonazepam

* Stereocenter

Fig. 1. Main metabolic pathway of meclonazepam

M11). The remaining nine metabolites were only observed in the human urines, supplemental Table I.

The fragmentation pattern for meclonazepam, as seen in Fig. 2, includes loss of the nitro group $(\mathrm{m} / \mathrm{z}, 284)$ followed by contraction of the 7-membered ring to a 6-, 5-, or 4membered ring, corresponding to the fragment ions at $\mathrm{m} / \mathrm{z}$ $255,238 / 239$, and 214, respectively. The base peak at $\mathrm{m} / \mathrm{z}, 204$ as well as the fragment ion at $\mathrm{m} / z, 179$ are produced by the loss of chloride from $\mathrm{m} / \mathrm{z} 238$ and 214, respectively. The fragmentation of amino- and acetamido-meclonazepam
(Figs. 3 and 4) show similar fragments as seen for meclonazepam with the exception that the amino- and acetamido-groups were more likely to be retained during fragmentation than the nitro-group.

\section{DISCUSSION}

In general, the metabolism of meclonazepam, Fig. 1, was found to be in accordance with the transformations previously

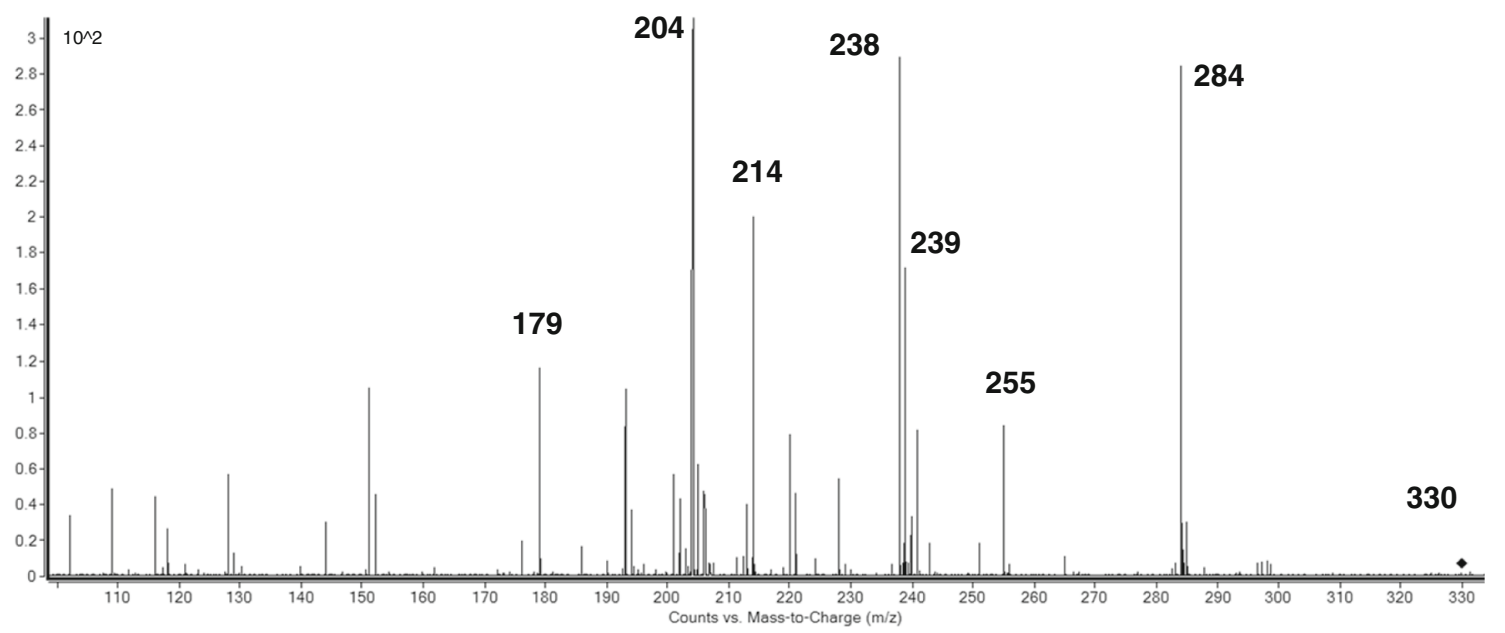

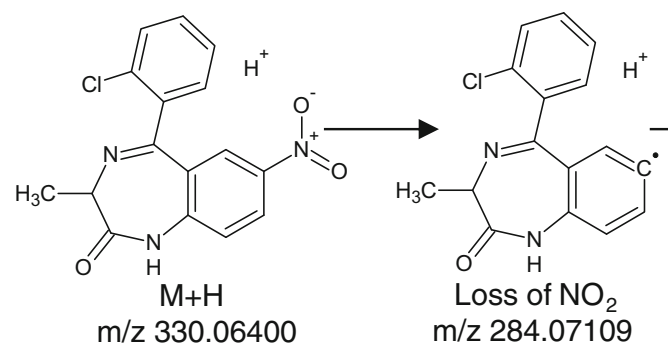<smiles>C=C1N=C(c2ccccc2Cl)c2ccccc2N1</smiles>

Ring contraction* $\mathrm{m} / \mathrm{z} 255.06835$<smiles>C=C1N=C(c2ccccc2Cl)C2=C[C+]C=CC12</smiles>

Loss of $\mathrm{Cl}$ $\mathrm{m} / \mathrm{z} 204.08078$<smiles>C=C1N=C(c2ccccc2Cl)c2c[c]ccc21</smiles>

Loss of $\mathrm{CO}$ and $\mathrm{NH}_{3}{ }^{*}$ $\mathrm{m} / \mathrm{z} 239.04963$<smiles>Clc1ccccc1C1=Nc2ccccc21</smiles>

Loss of $\mathrm{CH}_{3} \mathrm{CN}$ $\mathrm{m} / \mathrm{z} 214.04180$

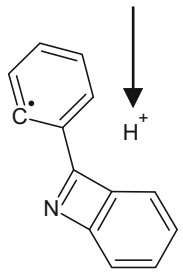

Loss of $\mathrm{Cl}$ $\mathrm{m} / \mathrm{z} 179.07295$

Fig. 2. Mass spectra and fragmentation pattern of meclonazepam. Asterisk several different configurations are possible 


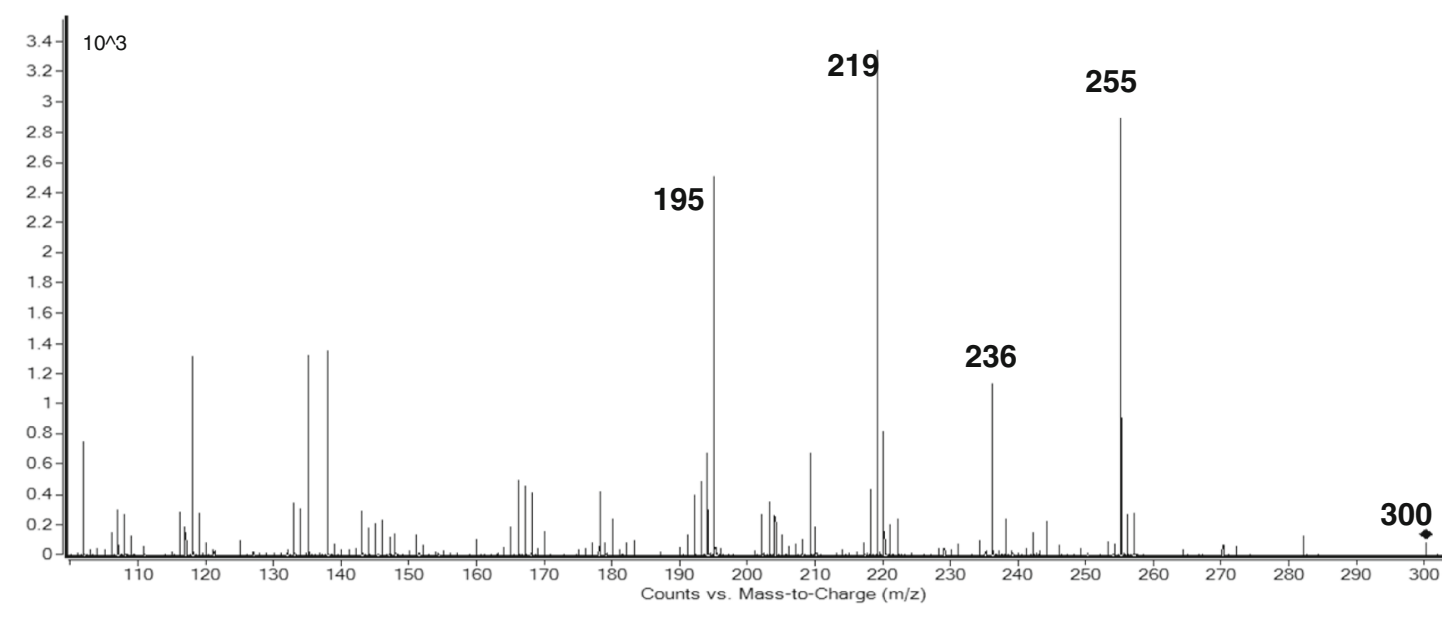<smiles>CN=C1Nc2ccc(N)cc2C(c2ccccc2Cl)=NC1C</smiles>

$\mathrm{M}+\mathrm{H}$ $\mathrm{m} / \mathrm{z} 300.08982$<smiles>Nc1ccc2c(c1)C(c1ccccc1Cl)=N2</smiles>
Loss of $\mathrm{CH}_{3} \mathrm{CHNH}$ $\mathrm{m} / \mathrm{z} 229.05270 \mathrm{NO}$
Ring contraction $\mathrm{m} / \mathrm{z} 272.09490 \mathrm{NO}$<smiles>CC1N=C(c2[c-]cccc2)c2cc(N)ccc2N1</smiles>
Loss of $\mathrm{HCl}$ $\mathrm{m} / \mathrm{z} 236.11822$<smiles>C=C1N=C(c2ccccc2Cl)c2cc(N)ccc21</smiles>
Ring contraction $\mathrm{m} / \mathrm{z} 255.06835^{*}$<smiles>Nc1ccc2c(c1)C(c1ccccc1)=N2</smiles>

\section{Loss of $\mathrm{CH}_{3} \mathrm{CN}$} $\mathrm{m} / \mathrm{z} 195.09168$

Fig. 3. Mass spectra and fragmentation pattern of amino-meclonazepam (M9). NO, fragment not observed. Asterisk several different configurations are possible

described for meclonazepam $(2,13)$ and other nitrocontaining benzodiazepines such as clonazepam (14-16), flunitrazepam (11), and nitrazepam (15). However, the hydroxylated metabolites reported by Coassolo et al. (12) and Huppertz et al. (2) were not confirmed.

The main metabolites clearly are amino-meclonazepam and acetamido-meclonazepam, which were most abundant in all human urine samples. Both are also formed in the mice model and by the hepatocytes. Notably, in HLM incubated under standard condition, only minimal amounts of the amino metabolite and none of the acetamido metabolite were identified. However, when meclonazepam was incubated with HLM under nitrogen, the amount of amino metabolite increases 140 times.

It is unknown which enzyme catalyzes the reduction of the nitro to the amino group in meclonazepam metabolism, but it has been shown that the conversion of clonazepam to amino-clonazepam is catalyzed by CYP3A4 (17). CYP3A4 can catalyze both oxidative and reductive biotransformations. However, the reductive capabilities are inhibited in the presence of excess oxygen (18). The fact that using the HLM under nitrogen dramatically increased the formation of the amino metabolite strongly indicates a similar mechanism for meclonazepam. When using HLM for metabolite identification studies, this effect should be considered for all substrates where a reduction is possible. A similar effect was not observed for the hepatocytes in this study, presumably as the intact cell ensures that the micro-environment at the endoplasmatic reticulum is similar to that in vivo.

In clonazepam metabolism, the acetamido metabolite is formed by NAT 2 (19) which is a cytosolic enzyme not present in HLM. Acetamido-meclonazepam is therefore not expected to be formed by HLM (under any conditions), but should be found in mice urine and hepatocyte incubates. The results of this study are in agreement with the results reported by Huppertz et al. (2) and Meyer et al. (13).

NAT 2 is also a polymorphic enzyme, and around half of a Caucasian population have a marked reduction in NAT 2 activity (20). In our study, ratios between the acetamido metabolite and the amino metabolite (in the hydrolyzed samples) were $0.47,0.39$, and 0.24 in cases $\mathrm{H} 2, \mathrm{H} 3$, and $\mathrm{H} 4$ while in case $\mathrm{H} 1$, the ratio was 1.21 which could possibly be caused by a higher NAT 2 activity in this case.

The fragmentation observed in our study differs from the fragments and spectra provided by Meyer et al. and Huppertz et al. Compared to the earlier studies, a more pronounced fragmentation 


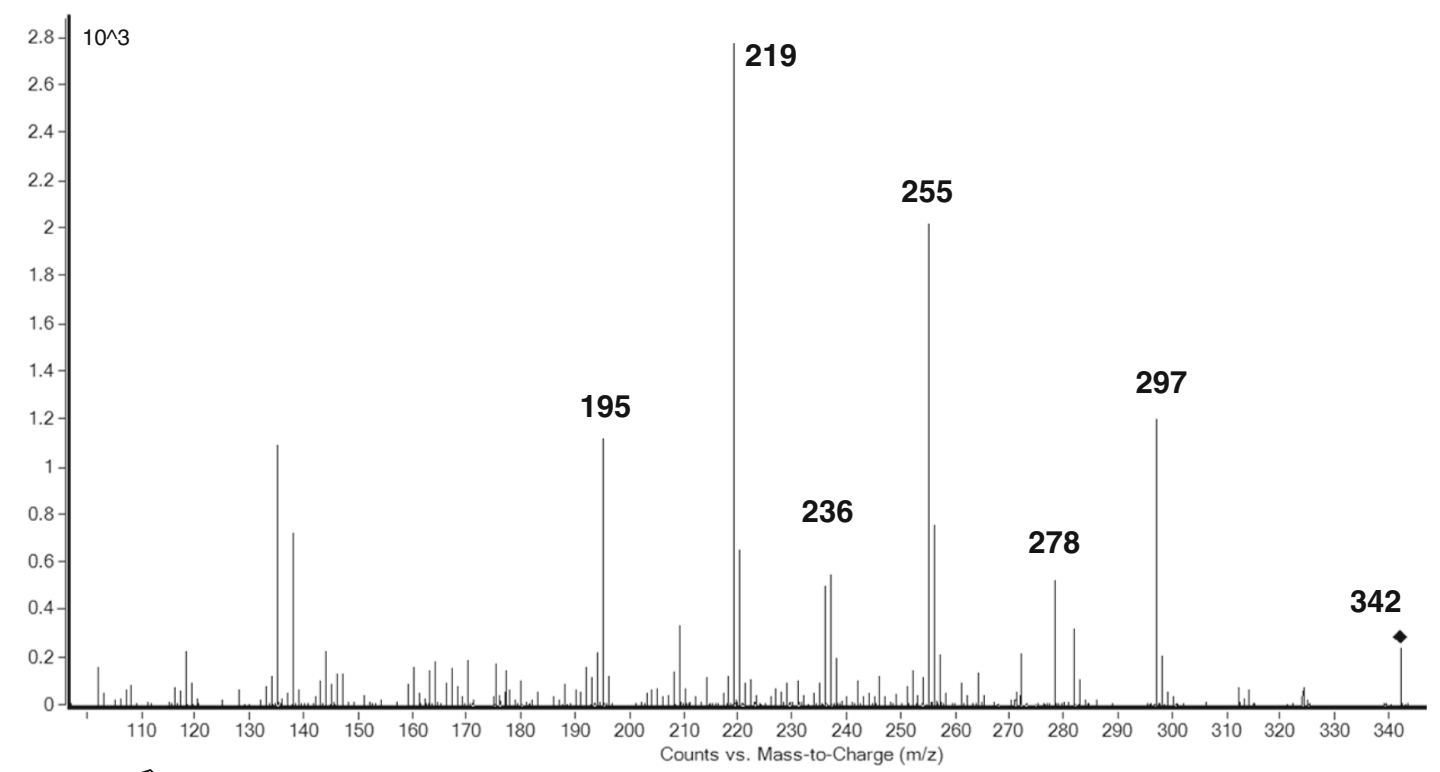<smiles>CC(=O)Nc1ccc2c(c1)C(c1ccccc1Cl)=NC(C)N2</smiles>

$\mathrm{M}+\mathrm{H}$ $\mathrm{m} / \mathrm{z} 342.10038$<smiles>CC1N=C(c2[c]cccc2)c2cc(N)ccc2N1</smiles>

Loss of $\mathrm{HCl}$ $\mathrm{m} / \mathrm{z} 278.12879$

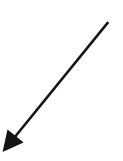

Ring contraction $\mathrm{m} / \mathrm{z} 314.10547 \mathrm{NO}$<smiles>CC1N=C(c2[c]cccc2)c2cc(N)ccc2N1</smiles>

Loss of $\mathrm{CH}_{2} \mathrm{CO}$ $\mathrm{m} / \mathrm{z} 236.11822^{\mathrm{a}}$<smiles>C=C1N=C(c2ccccc2Cl)c2cc(NC(C)=O)ccc21</smiles>

Ring contraction $\mathrm{m} / \mathrm{z} 297.07892$<smiles>Nc1ccc2c(c1)C(c1ccccc1)=N2</smiles>
Loss of $\mathrm{CH}_{3} \mathrm{CN}$
$\mathrm{m} / \mathrm{z} 195.09168$<smiles>C=C1N=C(c2ccccc2Cl)c2cc(N)ccc21</smiles>

Loss of $\mathrm{CH}_{2} \mathrm{CO}$ $\mathrm{m} / \mathrm{z} 255.06835^{\star}$<smiles>C=C1N=C(c2ccccc2)c2cc(N)ccc21</smiles>

Loss of $\mathrm{HCl}$ $\mathrm{m} / \mathrm{z} 219.09168$

Fig. 4. Mass spectra and fragmentation pattern of acetamido-meclonazepam (M11) NO, fragment not observed. Asterisk several different configurations are possible. ${ }^{a} \mathrm{~m} / \mathrm{z}$ could theoretically also be formed from $\mathrm{m} / \mathrm{z} 314$ by loss of $\mathrm{CH} 2 \mathrm{CO}$ followed by loss of $\mathrm{HCl}$

was observed showing only traces of the protonated molecule. A likely explanation for this is that a higher collision energy was used in this study. However, as different instruments have different collison cells, direct comparisons are difficult.

Furthermore, the structural suggestions for the fragments provided by Meyer et al. (13) are far from the only ones possible. Specifically, we postulate contractions of the diazepine ring to a 5membered or 4-membered ring, as in fragments 255 and 219 for amino-meclonazepam whereas Meyer et al. suggest the loss of the amino group followed by the formation of a triple bond within the benzene ring. A similar difference exists in the interpretation of the corresponding fragments of acetamido-meclonazepam as well as for fragment 195 of acetamido-meclonazepam. We postulate contraction of the diazepine ring to a 4-membered ring, whereas Meyer et al. suggest contraction of the benzene ring. The contraction of the diazepine ring to 5- and/or 4-membered rings has also been described for several other benzodiazepines, such as diazepam $(21,22)$, flurazepam (23), flunitrazepam $(21,23)$, and 3- hydroxy-flunitrazepam (23) and seems more plausible than the reactions suggested by Meyer $e t$ al.

In Table I, only metabolites also confirmed in at least one model system were included as this is a good indicator that the metabolite is generated from the parent drug. The first positive urine samples for a novel psychoactive substance (NPS), such as meclonazepam, that comes in to the lab are often are related in time and/or origin and might actually come from the same batch of drugs. As NPS products are often contaminated by synthesis by-products and/or mixtures of several NPS, there is a risk that an analyte is falsely attributed as a metabolite when in fact it is related to either a different drug or a synthesis by-product.

We suggest that amino- (M9) and acetamido (M11) meclonazepam are the best candidates for identification of meclonazepam intake. Furthermore, the parent drug is a valuable target as it was observed in three out of four human urines.

In this study, the concentration of parent in the samples might have been underestimated due to pre-analytical factors 
as there is evidence of poor stability under certain conditions. While no studies of meclonazepam stability in urine are known to us, Zaitsu et al. (24) reported that aminoflunitrazepam was degraded both by bacteria during storage at $4{ }^{\circ} \mathrm{C}$ and by adhesion to vessel surface. On a similar note, Coassolo et al. (12) reported that meclonazepam at $1 \mathrm{ng} / \mathrm{mL}$ in plasma was stable at $-20{ }^{\circ} \mathrm{C}$ for 3 months in polypropylene tubes but not in glass tubes nor at room temperature for $24 \mathrm{~h}$.

In this study, samples were analyzed both with and without hydrolysis to estimate the level of conjugation. This approach was used as glucuronides, and other conjugated metabolites are difficult to measure directly as they behave differently from unconjugated metabolites in the chromatographic separation and usually have lower ionization efficiency in positive electrospray ionization mode. While neither meclonazepam nor the major metabolites amino-meclonazepam (M9) and acetamido-meclonazepam (M11) appeared to be conjugated, some minor metabolites were (M8, M10, and M13).

\section{CONCLUSIONS}

We conclude that the major metabolites suitable as markers of meclonazepam intake are amino-meclonazepam (M9) and acetamido-meclonazepam (M11). These metabolites appear to be unconjugated in urine.

We also underline that a model system for metabolite identification should be carefully selected considering the expected metabolism of the tested drug. Reductive reactions may be prominent but may require anaerobic conditions usually not considered in standard in vitro experiment settings. Therefore, we believe that a more complete metabolic system, such as found in hepatocytes and animal models, is imperative to understand the complexity of metabolism of many NPS.

\section{ACKNOWLEDGEMENTS}

This study was conducted within the Strategic Research Area in Forensic Science (Strategiområdet forensiska vetenskaper) at Linköping University.

Open Access This article is distributed under the terms of the Creative Commons Attribution 4.0 International License (http://creativecommons.org/licenses/by/4.0/), which permits unrestricted use, distribution, and reproduction in any medium, provided you give appropriate credit to the original author(s) and the source, provide a link to the Creative Commons license, and indicate if changes were made.

\section{REFERENCES}

1. Szente A. Benzodiazepine derivatives. Google Patents; 1977.

2. Huppertz LM, Bisel P, Westphal F, Franz F, Auwärter V, Moosmann B. Characterization of the four designer benzodiazepines clonazolam, deschloroetizolam, flubromazolam, and meclonazepam, and identification of their in vitro metabolites. Forensic Toxicol. 2015;33(2):388-95. doi:10.1007/s11419-015-0277-6.

3. European Monitoring Center for Drugs and Drugs of Abuse. Sexual assaults facilitated by drugs or alcohol, EMCDDA Technical Data Sheet. 2008.

4. European Monitoring Center for Drugs and Drugs of Abuse. Perspective on Drugs, The misuse of benzodiazepines among high-risk opioid users in Europe. 2015.
5. Ansseau M, Doumont A, Thiry D, von Frenckell R, Collard J. Initial study of methylclonazepam in generalized anxiety disorder. Evidence for greater power in the cross-over design. Psychopharmacology. 1985;87(2):130-5.

6. Abdul-Ghani RA, Loutfy N, Hassan A. Experimentally promising antischistosomal drugs: a review of some drug candidates not reaching the clinical use. Parasitol Res. 2009;105(4):899-906. doi:10.1007/s00436-009-1546-2.

7. Baard AP, Sommers DK, Honiball PJ, Fourie ED, du Toit LE. Preliminary results in human schistosomiasis with Ro 11-3128. S Afr Med J. 1979;55(16):617-8.

8. O'Boyle C, Lambe R, Darragh A. Central effects in man of the novel schistosomicidal benzodiazepine meclonazepam. Eur J Clin Pharmacol. 1985;29(1):105-8.

9. Darragh A, Lambe R, Brick I, O'Boyle C. Antagonism of the central effects of 3-methylclonazepam. Br J Clin Pharmacol. 1982;14(6):871-2.

10. Verstraete AG. Detection times of drugs of abuse in blood, urine, and oral fluid. Ther Drug Monit. 2004;26(2):200-5.

11. Forsman M, Nystrom I, Roman M, Berglund L, Ahlner J, Kronstrand R. Urinary detection times and excretion patterns of flunitrazepam and its metabolites after a single oral dose. J Anal Toxicol. 2009;33(8):491-501.

12. Coassolo P, Aubert C, Cano JP. Plasma determination of 3methylclonazepam by capillary gas chromatography. J Chromatogr. 1985;338(2):347-55.

13. Meyer MR, Bergstrand MP, Helander A, Beck O. Identification of main human urinary metabolites of the designer nitrobenzodiazepines clonazolam, meclonazepam, and nifoxipam by nano-liquid chromatography-high-resolution mass spectrometry for drug testing purposes. Anal Bioanal Chem. 2016;408(13):3571-91. doi:10.1007/s00216-016-9439-6.

14. Petters I, Peng DR, Rane A. Quantitation of clonazepam and its 7amino and 7-acetamido metabolites in plasma by high-performance liquid chromatography. J Chromatogr. 1984;306:241-8.

15. Reynolds JEF, Martindale W. Royal Pharmaceutical Society. Martindale : the extra pharmacopoeia : [evaluated information on the world's drugs and medicines]. 31st ed. London: Royal Pharmaceutical Society; 1996.

16. Greenblatt DJ, Miller LG, Shader RI. Clonazepam pharmacokinetics, brain uptake, and receptor interactions. J Clin Psychiatr. 1987;48(Suppl):4-11.

17. Seree EJ, Pisano PJ, Placidi M, Rahmani R, Barra YA. Identification of the human and animal hepatic cytochromes P450 involved in clonazepam metabolism. Fundam Clin Pharmacol. 1993;7(2):69-75.

18. Peng DR, Petters I, Rane A. Nitroreduction of clonazepam in human foetal liver microsomes and hepatocyte cultures. Biochem Soc Trans. 1984;12(1):39-42.

19. Olivera M, Martinez C, Gervasini G, Carrillo JA, Ramos S, Benitez J, et al. Effect of common NAT2 variant alleles in the acetylation of the major clonazepam metabolite, 7aminoclonazepam. Drug Metab Lett. 2007;1(1):3-5.

20. Walker K, Ginsberg G, Hattis D, Johns DO, Guyton KZ, Sonawane B. Genetic polymorphism in N-Acetyltransferase (NAT): Population distribution of NAT1 and NAT2 activity. J Toxicol Environ Health Part B Crit Rev. 2009;12(5-6):440-72. doi:10.1080/10937400903158383.

21. Niessen WM. Fragmentation of toxicologically relevant drugs in positive-ion liquid chromatography-tandem mass spectrometry. Mass Spectrom Rev. 2011;30(4):626-63. doi:10.1002/mas.20332.

22. Risoli A, Cheng JB, Verkerk UH, Zhao J, Ragno G, Hopkinson $\mathrm{AC}$, et al. Gas-phase fragmentation of protonated benzodiazepines. Rapid Commun Mass Spectrom. 2007;21(14):2273-81. doi:10.1002/rcm.3084.

23. Smyth WF, McClean S, Ramachandran VN. A study of the electrospray ionisation of pharmacologically significant 1,4-benzodiazepines and their subsequent fragmentation using an ion-trap mass spectrometer. Rapid Commun Mass Spectrom. 2000;14(21):2061-9. doi:10.1002/1097-0231(20001115)14:21<2061::AIDRCM135>3.0.CO;2-8.

24. Zaitsu K, Miki A, Katagi M, Tsuchihashi H. Long-term stability of various drugs and metabolites in urine, and preventive measures against their decomposition with special attention to filtration sterilization. Forensic Sci Int. 2008;174(2-3):189-96. doi:10.1016/j.forsciint.2007.04.224. 